\title{
Darmbakterien sind Alleskönner
}

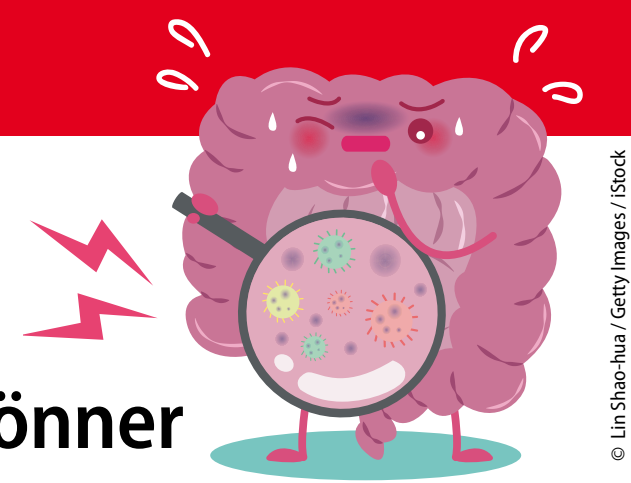

\begin{abstract}
— Auf dem diesjährigen Kongress der Deutschen Gesellschaft für Verdauungsund Stoffwechselkrankheiten konnte man den Eindruck gewinnen, als gebe es nur noch ein wichtiges Forschungsgebiet, nämlich das der Darmflora. (Dabei ist die Terminologie eigentlich nicht korrekt; denn Bakterien sind ja keine Pflanzen, also müsste es „Darmfauna“ heißen. Aber so richtige Tiere sind sie eben auch nicht. Vielleicht kann man sich auf "Flaura" einigen.)

Die Darmbakterien sind plötzlich zum Liebling der Gastroenterologen mutiert - doch warum? Ganz einfach:
\end{abstract}

Die falschen Bakterien machen dick, dumm, hässlich, faul, krank und depressiv. Umgekehrt wird mit den richtigen Keimen den Magen-Darm-Spezialisten die wundersame Fähigkeit verliehen, ihre Patienten gesund, schlank, schön und schlau zu machen.

Glaubt man den Studien, so gibt es kaum ein gastroenterologisches Krankheitsbild, an dem nicht die Bakterien (mit) schuld sind: Reizmagen, Reizdarm, bakterielle Fehlbesiedlung, Divertikulose, NSAR-Enteropathie, chronisch-entzündliche Darmerkrankungen etc. Dabei ist nicht die Menge an Bakterien, sondern die Typenvielfalt das Entscheidende. Je mehr Sorten im Darm, umso gesünder ist der Mensch. Wer nur wenige Spezies aufzuweisen hat, ist arm dran (s. auch Beitrag auf S. 22).

So lautet die Zauberformel: Mikrobiommodulation. Dahinter verbirgt sich ein heroisch anmutendes Therapiekonzept, die fäkale Stuhltransplantation. Die Sache scheint zu funktionieren. Nur mit der Akzeptanz gibt es noch Probleme. Doch Böses muss man mit Bösem vertreiben. Und entscheidend ist bekanntlich, was hinten rauskommt.

Dr. Peter Stiefelhagen

\section{Hilferufe aus der Lunge}

\section{Schluckauf war Quälgeist und Lebensretter in einem}

\author{
Schluckauf kann, wenn er lange anhält, äußerst lästig sein. Im Falle eines 60-jährigen Mannes war \\ das Gehickse jedoch nicht nur das, sondern der einzige Hinweis auf einen lebensbedrohlichen Zustand ...
}

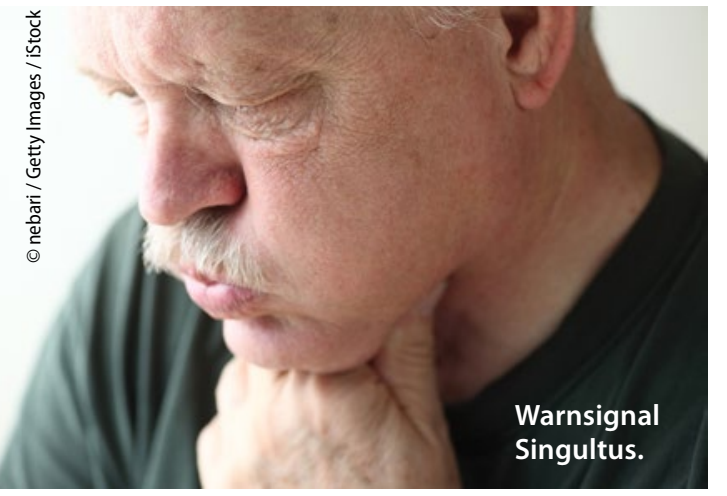

Zwei Tage nach einer elektiven Knieoperation stellte sich bei dem 60-Jährigen ein hartnäckiger Schluckauf ein, der sich jedem Hausmittel widersetzte. Nach drei Tagen war der Mann verzweifelt ge- nug, um sich zur nächstgelegenen Klinik aufzumachen.

Die Routineuntersuchung in der Notaufnahme erbrachte zunächst keine Auffälligkeiten. Die Blutwerte waren im Normbereich, das EKG zeigte einen normalen Sinusrhythmus mit einer Frequenz von $82 / \mathrm{min}$., und auch das Röntgenbild wies keinen pathologischen Befund auf. Der Patient berichtete weder über Atemnot noch hatte er Brustschmerzen, Palpitationen oder Husten.

Weil die Ärzte angesichts der vorausgegangenen Op. dem Frieden nicht trauten, entschlossen sie sich zu einer Kontrast-CT-Untersuchung. Diese zeigte in der rechten Lunge mehrere Emboli sowie angrenzend an die rechte Zwerchfellhälf- te eine dreieckige Verschattung. Hier musste ein Infarkt stattgefunden haben.

Offenbar hatte der Infarkt in der Lunge den Schluckauf ausgelöst: Durch die Nähe des betroffenen Lungenabschnitts zum Zwerchfell wurde wahrscheinlich der N. phrenicus oder der Zwerchfellmuskel stimuliert, was $\mathrm{zu}$ ständigen Kontraktionen führte.

Nachdem sich der Verdacht auf Lungenembolie bestätigt hatte, erhielt der $\mathrm{Pa}$ tient zunächst ein niedermolekulares Heparin, danach ein direktes orales Antikoagulans. Zehn Tage später war der Schluckauf - in diesem Fall Quälgeist und Retter in einem - verschwunden.

- Dr. Elke Oberhofer

- Thind M. Am J Med 2017, online 8. September 2017 